\title{
FORTALEZAS Y DEBILIDADES DE LA LEY DE SEGUROS (733) EN NICARAGUA
}

Victor Manuel Habed Blandon*

\begin{abstract}
Resumen
Es indiscutible la importancia que tienen los seguros en Nicaragua y en el mundo. Importancia que se materializa a nivel personal, ya que otorga seguridad y satisfacción a las personas; a nivel familiar ya que concede estabilidad en el hogar y a nivel nacional ya que los seguros operan como impulsores de la economía nacional tal como lo hace la banca.

Sin embargo en Nicaragua no poseemos, aún, una legislación especializada aplicable a los seguros (ni al derecho de seguro, ni al contrato de seguro), salvo unas disposiciones obsoletas contenidas en el Código de Comercio y en algunas resoluciones de la Superintendencia de Bancos, ahora bien, se aprobó una Ley General de Seguros, Reaseguros y Fianzas, que en lugar de dinamizar y regular la actividad asegurativa en Nicaragua, lo que hace es estar enteramente encaminada a responder a las exigencias establecidas por organismos internacionales y por el Tratado Libre Comercio entre Estados Unidos Centroamérica como parte signataria del TLC (DR-CAFTA), aprobado y ratificado por nuestra Asamblea Nacional, asumiendo entre otros compromisos, el contenido en el Anexo 12.9.2, sección F, numeral 7; quedando así por fuera, lo relativo a la regulación de los contratos de seguros y a la solución de posibles situaciones jurídicas que puedan nacer entre el asegurado y el asegurador, entre los Intermediarios de Seguros y entre los beneficiarios, en su caso.

Al aprobar esta Ley, quedaron muchos vacíos y deficiencias que serán expuestas, de manera técnica y objetiva, en este artículo investigativo. Desde luego no expondré todos aquellos títulos ni capítulos ni artículos de la Ley, sino aquellos que sean de mayor relevancia para la actividad del Intermediario de Seguro, de las Empresas Aseguradoras y del Contrato de Seguro.
\end{abstract}

Palabras claves: Aseguradoras, Asegurado, Contrato de seguro, Póliza de seguro, Superintendencia de Bancos

\section{Abstract}

It is unquestionably the importance of insurance in Nicaragua and the world. Importance immaterializes at personal level, because it provides security and satisfaction to the people; at the family level as it gives stability at home and nationally operates as drivers of the national economy as does the bench.

However Nicaragua do not possess, yet, specific legislation applicable to insurance

(not the right insurance, or to the insurance contract), except some outdated provisions of the Commercial Code and in some resolutions of the Superintendence of Banks, however a General Law on Insurance, Reinsurance and Bonds was approved, that in instead of activating and regulating insurance activity in Nicaragua, making designed to be entirely meet the requirements set by international bodies and the Free Trade Agreement with the United States as a signatory to the TLCCAFTA assuming among other commitments, those contained in Annex 12.9.2, Section F, paragraph 7; and are kept outside; regard to the regulation of insurance contracts and the settlement of possible legal situations that may arise between the insured and the insurer among insurance intermediaries and beneficiaries, if any.

By passing this law, there are many gaps and deficiencies are exposed, technical and objectively in this article. Of course I will not discuss all those titles, chapters or sections of the Law, but those that are most relevant to the activity of the Insurance Broker, Insurance Companies and the Insurance Contract.

Keywords: Insurers, Insured, Insurance contract, Insurance policy, Superintendency of Bank

* Máster en Derecho Internacional Público. Docente del Departamento de Derecho, UNAN - Managua. 


\section{INTRODUCCION}

L a actual Ley 733, Ley de Seguros, Reaseguros y Fianzas, fue aprobada por la Asamblea Nacional el día quince de julio del año 2010, publicada en las Gacetas, Diario Oficial de Nicaragua los días 25, 26 y 27 de agosto de ese mismo año.

Los Legisladores, en su exposición de dictamen favorable de la Ley, del 18 de marzo de 2010, señalan como sus fortalezas las siguientes :

a.- "Ley de Reformas a la Ley General de Instituciones de Seguros", fue presentado el 12 de Marzo del 2009 ante Primer Secretaría de la Asamblea Nacional, por el Presidente de la República Daniel Ortega Saavedra.

b.- Este Proyecto de Ley se origina a partir de exigencias económicas establecidas por el Tratado Libre Comercio entre Estados Unidos Centroamérica como parte signataria del TLC (DR-CAFTA), aprobado y ratificado por nuestra Asamblea Nacional, asumiendo entre otros compromisos, el contenido en el Anexo 12.9.2, sección F, numeral 7 , en el cual debemos permitir que empresas de los Estados Unidos de América proveedoras de servicios de seguros, se establezcan en el territorio nacional y puedan ofertar este producto financiero teniendo nuestro país la facultad de normar su regulación, incluyendo entre otras sus características, estructura, relación con su casa matriz, requisitos de capital, reservas técnicas y obligaciones relativas al patrimonio de riesgo, inversiones, entre otras. Este Tratado internacional dispone la entrada al país de empresas proveedoras de servicios de seguros de EE.UU. cuatro años posterior al periodo de su entrada en vigencia del Tratado Libre Comercio el mismo. La Ley original instituyó el establecimiento de sucursales de empresas aseguradoras extranjeras con patrimonio propio, siendo regulados por los artículos del 19 al 26. Sin embargo, por el incipiente desarrollo del sistema financiero privado nacional, los legisladores en 1996, aprobaron la Ley No. 227, con lo cual reformaron la Ley general de instituciones de seguros, que en su parte medular derogó los artículos 20, 21, 22, 23, 24, 25 y 26, todos ellos referidos a la constitución, autorización y operación de las sucursales extranjeras de empresas aseguradoras. En su momento esta medida perseguía de manera temporal protegía y beneficiaba al sector financiero nacional en la actividad de seguro como operadores exclusivos del sistema.

c.- La Comisión económica de la Asamblea Nacional, con el apoyo de la Superintendencia de Bancos y Otras Instituciones Financieras, trabajó en la reelaboración de una nueva Ley íntegra, moderna, promotor de la seguridad y garantías a los asegurados, que desarrolla el fortalecimiento de las funciones de supervisión y regulación de la Superintendencia de Bancos, y que promueve la transparencia y la competencia de las instituciones prestadoras de este servicio en el mercado de seguros, reforzando el capital de riesgo, capital mínimo y las reservas pecuniarias con que deben de operar las compañías aseguradoras para resguardar el dinero de los clientes y finalmente afianza la calidad de las inversiones que deben de realizar estas empresas.

d.- La Comisión de Producción, Economía y Presupuesto, consultó, para su 
elaboración, a la Superintendencia de Bancos; a la Asociación Nicaragüense de Aseguradoras Privadas (ANAPRI); a la Cámara Nicaragüense de Correduría de Seguros; al Banco Central; Compañías Privadas de Seguros y el INISER; y algunos Intermediarios de Seguros.

e.- Los representantes de dichas dependencias que comparecieron ante la Comisión, manifestaron sus opiniones, criterios, aportes y sugerencias técnicas sobre el proyecto de ley. En este proceso de consulta los Diputados de la Comisión coincidieron con la Superintendencia de Bancos, en elaborar un nuevo Proyecto de Ley a partir de la Reforma presentada por el Presidente de la República ya que el ordenamiento jurídico anterior requería incorporar nuevos elementos para tratar de garantizar la protección de los derechos de los usuarios o clientes quienes confían sus primas a las instituciones de seguros, reaseguros o fianzas y a sus intermediarios, como asimismo vigilar por el respeto de los mismos frente al desenvolvimiento del mercado de seguro.

f.- Así mismo consideraron importante dotar de mayor seguridad jurídica a la Industria de Seguros del país ya que el actual marco legal que los rige tiene naturaleza y origen de Decreto Ley. Como consecuencia de la propuesta del presente dictamen la base fundamental será una Ley de la República la cual podrá ser reglamentada y desarrollada vía norma prudencial por la SIBOIF.

g.- El objetivo de la Ley es dotar a la nación de una moderna y eficiente legislación sobre el mercado de seguro, que comprenda el funcionamiento transparente de sus instituciones, el avance tecnológico actual, el rol del ente supervisor y regulador de esas instituciones, cuya función especial es promover un ambiente favorable y de confianza a los asegurados que invierten su dinero en la protección de sus bienes y de su salud.

h.- Esta Ley contiene cambios novedosos y significativos con respecto a la Ley anterior, los que mencionamos entre otros, los siguientes:

1) Amplía y brinda nuevas facultades al órgano regulador (SIBOIF).

2) Abre el mercado a las empresas de seguros extranjeros.

3) Promueve la protección de los derechos de los usuarios.

4) Regula la fusión de las sociedades de seguros.

5) Modifica y actualiza los montos del capital social obligatorio.

6) Norma y regula las facultades de la SIBOIF en materia de sanciones.

7) Introduce la figura del Contralor normativo y detalla el procedimiento para los planes de normalización y liquidación.

8) Crea una nueva rama de seguros, el micro seguro.

9) Actualiza la Ley de conformidad a los avances tecnológicos.

10) Destruye la formación de estructuras monopólicas sobre la fusión de las sociedades de seguros que distorsionen los precios del mercado, limite los servicios y restringa la libre competencia en los mercados que participe. 
11) Se da mayores facultades a la Superintendencia para la aplicación de sanciones pecuniarias (multas) a las sociedades y empresas prestadoras de servicios de seguro que infrinjan las disposiciones de esta ley.

La Ley cuenta con nueve títulos y 195 artículos. Y a pesar de estar bien fundamentada en la exposición de dictamen favorable y por la Superintendencia de Bancos, presenta muchos vacíos, debilidades y deficiencias.

\section{CUERPO DEL TRABAJO}

\section{En cuanto a los aspectos generales de la Ley:}

1.- La Ley 733 recibe el nombre de "Ley General deSeguros, Reaseguros y Fianzas", pero:

a) No hay ningún artículo, a excepción de la definición, que regule las fianzas.

b) Solamente son 13 artículos (del 93 al 105), que regulan el reaseguro.

c) El Título de la Ley está errado, ya que no es una Ley de Seguros, Reaseguros y Fianzas, sino una Ley que Regula a las Instituciones de Seguros. En Costa Rica, por ejemplo, recibe el nombre de "Ley Reguladora del Mercado de Seguros", en Guatemala se llama "Ley de la Actividad Aseguradora", en Honduras se titula "Ley de Instituciones de Seguros y Reaseguros, en El Salvador recibe el nombre de "Ley de Sociedades de Seguro" y en República Dominicana se titula "Ley sobre Seguros y Fianzas"

2.- Esta Ley Tiene por objeto regular la constitución y el funcionamiento de las sociedades de seguros, reaseguros y fianzas y sucursales de sociedades de seguros extranjeras. Procurando su liquidez y solvencia, a fin de generar una sana competencia y cartera de productos diversificados (Art. 1). Lo relativo a la regulación de las aseguradoras extranjeras había sido derogado en la anterior Ley General de Instituciones de Seguros.

3.- Para los efectos de aplicación de las disposiciones de la Ley 733, señala un glosario de términos (Art. 3). El glosario de términos no estaba contenido en la Ley de Instituciones de Seguros anterior ni en ninguna otra ley relacionada al seguro. Este glosario solamente es señalado en las leyes de república Dominicana y Honduras, pero no en la de Costa rica, El Salvador y Guatemala.

Sin embargo la terminología señalada en la Ley no contempla términos básicos en seguros tales como "seguro", "asegurador" ni "póliza de seguro".

Al analizar los términos definidos, que interesan en esta exposición, tienen las siguientes debilidades:

a) Adenda: "Documento que se une a una póliza en que se establecen ciertas modificaciones o declaraciones en el contenido anterior de estas, dejándola a un nuevo tenor". Este término "adenda" no es el utilizado a nivel internacional, ya que el empleado es "anexo". Además falta señalar que este documento es un escrito complementario y pasa a formar parte integrante de la póliza.

b) Asegurado: "Es la persona natural o jurídica que, mediante el pago de una prima, recibe la protección de la sociedad de seguros, lo que le da derecho, en virtud de lo establecido 
en la póliza de seguro, al cobro de las indemnizaciones que se produzcan". Esta definición confunde las figuras de tomador de seguro y beneficiario. Olvida que el asegurado puede ser asegurado en si mismo o en sus bienes o sus intereses económicos y que es la que está expuesta a los riesgos cubiertos en la póliza.

c) Beneficiario: "Persona designada en la póliza por el asegurado o el contratante como titular de los derechos indemnizatorios que en dicho documento se establecen". Esta definición presenta las siguientes deficiencias: no refiere que el beneficiario puede ser persona natural o jurídica; no señala que el beneficiario puede recibir los beneficiarios totales o parciales acordados; no señala que el beneficiario debe ser designado por el contratante una vez que haya autorización del asegurado.

d) Contratante: "Persona que suscribe con una entidad aseguradora una póliza o contrato de seguro". Se refiere al tomador de seguro, pues contratantes son ambas partes ya que el seguro es contrato bilateral. No señala la principal obligación del tomador que es el pago de la priman y no habla que requiere interés asegurable o la autorización del asegurado.

e) Contrato de seguro: "Contrato mercantil de prestación de servicios futuros, por el cual una sociedad de seguros se obliga mediante el pago de una prima, a indemnizar a otra persona natural o jurídica, de las pérdidas o daños que sufra como consecuencia de acontecimientos probabilístico, fortuitos o de fuerza mayor, o a pagar una suma según la duración o los acontecimientos de la vida de una o varias personas". Esta definición es la misma, con algunas mejoras, de la ofrecida por el artículo 535 del Código de Comercio de 1917.

f) Indemnización: "Importe que está obligado a pagar contractualmente la entidad aseguradora en caso de producirse un siniestro. Es en consecuencia, la contraprestación que corresponde al asegurador frente a la obligación de pago de prima del asegurado. El fin de la indemnización es conseguir una reposición económica del asegurado afectado por un siniestro, bien a través de una sustitución del objeto dañado o mediante la entrega de una determinada cantidad de dinero, o bien mediante la prestación de servicios. Sin embargo, en cualquiera de ambos casos, debe haber una doble limitación en la indemnización: por un lado no puede ser superior a la suma asegurada en la póliza para el riesgo afectado por el siniestro; $y$ de otro que no puede exceder del valor real del objeto dañado inmediatamente antes de producirse el accidente". Olvida la Ley que la indemnización debe ser pagada no en todos los casos, sino en aquellos en que proceda una vez completada toda la documentación y que se haya comprobado la ausencia de frade.

g) Siniestro: "Es la realización del riesgo asegurado previsto en el contrato de seguro, del cual surge la obligación indemnizatoria". La ley no contempla todas las posibilidades de ocurrencia del siniestro en otros tipos de seguros como el de responsabilidad civil que no ocurre el siniestro al momento de daños o la muerte del tercero.

4.- En cuanto a la Superintendencia de Bancos se le otorga, además de las atribuciones señaladas en la Ley de la 
Superintendencia de Bancos en su artículo 3, las indicadas en el artículo 6 de la Ley, relacionadas con la supervisión de las aseguradoras, auxiliares de seguros e intermediarios, que le conceda la facultad de investigación. Sin embargo creemos que la Superintendencia no está facultada para investigar ya que esto se trata de una labor policial. (Números 4 y 5).

5.- La Ley entiende como actividades relacionadas con seguros, reaseguros y fianzas las enumeradas en el artículo 7 de la Ley. Olvida este artículo que el seguro y fianza es una transferencia de riesgos asegurables a los que están expuestas las personas, con el fin de dispensar en un colectivo la carga económica que pueda generar su ocurrencia. Y el reaseguro es que la reaseguradora acepta la cesión de todo o parte del riesgo asumido por una entidad aseguradora en virtud de los contratos de seguro subyacentes.

6.- En cuanto a su regulación, las aseguradoras, reaseguradoras e intermediarios se rigen por la ley 733, la Ley General de Bancos, en lo que le fuere aplicable, la Ley de la Superintendencia de Bancos, Normas emanadas por el Consejo Directivo de la Superintendencia, las instrucciones que dicte el Superintendente y en lo no previsto se sujetarán a la legislación común (artículo 8). Entendemos que las instrucciones del Superintendente deben ser aquellas de carácter general y no particular.

\section{En cuanto a las Compañías Aseguradoras:}

7.- Casi todo el clausulado que regula la constitución delas compañías aseguradoras son copia de la Ley General de Bancos. A continuación expongo estas copias fieles:

a.- Los acuerdos y resoluciones de la Junta Directiva, sea en forma física o en forma no física, constarán en el libro de actas y deberá ser firmado por el Presidente y el Secretario. La participación de los Directores, en las sesiones físicas, se demostrará con su firma en el documento de asistencia que pasa a formar parte del acta respectiva. Cuando sean acuerdos alcanzados en reuniones no físicas, los Directores, deberán posteriormente ratificar en documento aparte con su firma su participación en la sesión. Las certificaciones de las actas pueden ser libradas por el Secretario de la Junta Directiva o por Notario en su defecto. (Art. 42). Lo anterior es una copia fiel del artículo 27 de la Ley General de Bancos.

En la Ley no se regula nada relacionado con los acuerdos alcanzados por las aseguradoras extranjeras para con su relación con la Sucursal.

b.- Los miembros de la Junta Directiva podrán ser personas naturales o personas jurídicas, accionistas o no. $\mathrm{Si}$ son personas naturales no pueden ser menores de 25 años, de reconocida honorabilidad y competencia profesional. Si son personas jurídicas ejercerán el cargo a través de un representante que debe cumplir con los requisitos anteriores y será responsable personal y solidariamente por sus actuaciones conjuntamente con el accionista que representa (Art. 43). El Superintendente podrá dejar sin efecto cualquier elección o nombramiento que no cumpla los requisitos de idoneidad y competencia para dicho cargo (Art. 50). Este artículo es una copia del artículo 28 de la Ley General de Bancos

c.- Los miembros de la Junta Directiva, sin perjuicios de otras sanciones que les correspondan, responden personal y solidariamente con sus bienes de 
las pérdidas que se irroguen a la sociedad por autorizar operaciones prohibidas y por los actos efectuados o resoluciones adoptadas en contravención a las leyes, las Normas dictadas por el Consejo Directivo de la Superintendencia, las instrucciones $\mathrm{y}$ órdenes del Superintendente y demás disposiciones aplicables, quedando exentos los que hubiesen hecho constar su voto disidente en el acta de sesiones correspondiente y los que estuviesen ausentes durante dicha sesión (Art. 47). Las mismas responsabilidades corresponden a los directores, funcionarios o empleados que revelaren o divulgaren cualquier información de carácter confidencial sobre asuntos comunicados a la propia sociedad o que en ella se hubiese tratado, así como los mismos directores, funcionarios o empleados que aprovecharen tal información para fines personales. (Art. 48). Este artículo es textual de los artículos 35 y 36 de la Ley de Bancos.

8.- Las sociedades de seguros y la sucursales de aseguradoras extranjeras que practiquen varias de las operaciones $y$ ramos de seguros, deberán llevar los libros, registros y auxiliares en forma separada para los ramos de vida y de seguros generales, conforme a las normas que dicte el Consejo Directivo. En este sentido es necesario preguntarse ¿cuáles son los seguros generales? El artículo 66 divide las operaciones de seguro y no mencionada nada relativo a los seguros generales. ¿Qué sucede con los otros ramos de seguro, se quedan sin contabilidad?

\section{En cuanto al contrato de seguro:}

9.- Esta Ley contempla aspectos relacionados con el contrato de seguro que no estaban regulados por la Ley anterior. Solamente las legislaciones de Honduras y República Dominicana abordan, dentro de la Ley de Instituciones de Seguros, aspectos relacionados con el contrato.

Pero a pesar de lo anterior esta Ley no desarrolla nada relacionado con:

a) Prescripción de acciones contra las aseguradoras.

b) Riesgos cubiertos y exclusiones.

c) Idioma de las pólizas.

d) Nulidad del contrato.

e) Moneda de la prima o de la indemnización.

10.- En lo relativo a las pólizas de seguros podemos decir:

a.- El Superintendente revisará y aprobará las condiciones generales, condiciones particulares, solicitud del seguro, cuestionarios, adenda y demás documentos que formen parte integrante de las pólizas, así como las notas técnicas respectivas, para nuevos planes y/o modificaciones a las ya existentes.

b.- En la carátula de las Condiciones Generales y Condiciones Particulares, y en todos los documentos integrantes de la póliza, deberá figurar con caracteres destacados el número y fecha de resolución del Superintendente a través de la cual fue aprobada. (art. 73).

El Superintendente no podría revisar las adenda, ni las condiciones particulares ya que son documentos personalizados para cada cliente. Además no puede revisar todos los documentos que conforman la póliza 
porque puede estar compuesto de un gran número de ellos y en ocasiones son enviados con posterioridad por el asegurado. Este artículo no señala si la revisión y aprobación funcionará para aquellos planes nuevos o para los ya existentes.

Esta revisión, se contradice con la agilidad de la venta de pólizas señalada en el artículo 185 de la Ley 733 que señala "Se podrá contratar seguros a distancia o por vía electrónica, en cuyos casos no será necesaria la presencia física simultánea del asegurado o contratante y el asegurador. Estos contratos producirán todos los efectos previstos en la Ley para contratos presenciales, siempre que cumplan con los requisitos que las leyes especiales en materia de contratación y firma electrónica establezcan.

56 c.- El Superintendente instruirá los cambios necesarios, cuando las pólizas o los modelos de cláusulas adicionales, se opongan a la ley; asimismo cuando de la revisión de las notas técnicas se derive que las tarifas no son suficientes para cubrir los riesgos, o cuando los recargos, intereses o provisiones sean de igual manera insuficientes. La Superintendencia registrará las pólizas y los modelos de cláusulas adicionales (art. 73) La Ley habla de cláusulas adicionales, pero no están definidos en el contenido de la misma.

d.- La aseguradora estará obligada a indemnizar al asegurado por los siniestros que ocurra, cuando la prima pagada a la fecha sea igual o superior a la prima devengada al momento de ocurrir el siniestro. En caso contrario, es decir, que las primas en mora correspondan a un período ya devengado, la aseguradora no estará obligada a indemnizar al asegurado en caso de que se produzca el siniestro. (art. 78). La ley no regula nada referente al período de gracia que debe existir antes de la cancelación de la póliza. Además las aseguradoras deben indemnizar una vez que se hayan completado toda la documentación exigida y que se haya comprobado la existencia real del siniestro, y que se haya verificado que el contrato no excluya de manera precisa determinados acontecimientos, lo que no es abordado por la Ley.

e.- Toda solicitud de prórroga, renovación, modificación o restablecimiento de un contrato podrá ser presentada por el asegurado, en forma directa o por medio de intermediario nombrado, por cualquier medio escrito o electrónico con acuse o comprobación de recibo. La compañía de seguro deberá responder la solicitud en un plazo no mayor de 72 horas. Si la aseguradora no responde dentro de este plazo, la respectiva solicitud se tendrá como aceptada.

Lo dispuesto en el párrafo anterior no es aplicable a las solicitudes de aumento de suma asegurada, inclusión de nuevos riesgos y en ningún caso a seguro de personas. (art. 79). Esta nueva disposición contradice lo que está señalado en el artículo 2452 del Código Civil que toma como no aceptada la solicitud caso de silencio.

f.- Si el asegurado no estuviere de acuerdo con los términos del contrato suscrito o póliza emitida por la sociedad de seguro, podrá resolverlo dentro de los 30 días siguientes de haber recibido el contrato o póliza, si no concordare con los términos de su solicitud. En el mismo plazo podrá solicitar la modificación del texto en lo referente a las condiciones especiales del contrato. El silencio se entenderá como conformidad con la póliza o contrato. 
g.- En caso de ocurrir un siniestro antes de solicitada y/o aceptada por la sociedad de seguros cualquier rectificación o modificación durante el tiempo establecido en el párrafo anterior, ambas partes se sujetarán a lo establecido en la póliza. Se sujetarán a lo establecido en la solicitud cuando, las condiciones de la póliza de seguros no concuerden con la solicitud del asegurado, habiendo este pagado la prima correspondiente a lo solicitado. (art. 80).

h.- Cumplidos los requisitos previstos en la póliza por parte del asegurado, aceptado el siniestro por parte de la aseguradora y concluido el plazo para indemnizar, el retraso o mora en el pago de la indemnización por parte de la sociedad de seguro, por causas no imputables al asegurado o beneficiario, pagará un interés mensual equivalente al promedio que estuviere cobrando la banca comercial para los préstamos de corto plazo a partir de la fecha en que debió realizar el pago de la indemnización; este promedio se determinará en cada caso conforme a los datos registrados en el Banco Central de Nicaragua (art. 82).

En cuanto a los Intermediarios y Auxiliares de Seguros:

11.- Desapareció la obligación de utilizar Intermediarios de Seguros en la contratación de seguros de incendio de bienes muebles o mercaderías (art. 84 LGIS anterior).

12.- Tres artículos de este Título está recurrido de amparado por la Cámara Nicaragüense de Corredurías de Seguro.

13.- Este Título hace una unión de dos figuras distintas: el Intermediario de
Seguro y el Auxiliar de Seguros. Ambos realizan distintas funciones. Debieron haber estado en títulos separados.

14.-Este Título desarrolla poco en lo relativo a las comisiones de los Intermediarios. Y no desarrolla nada relativo a los servicios de intermediación de seguros del comercio transfronterizo.

15.- No se desarrolla lo relativo a la Intermediación de Seguro que realizan los Bancos.

16.- No se desarrolla nada relativo a los Intermediarios de Reaseguro.

17.- Desarrolla los deberes de los Intermediarios de Seguro, los Ajustadores de Reclamo y los derechos de los Evaluadores de Riesgo, pero no desarrolla las funciones de los otros Auxiliares del Seguro: Investigador de Siniestro, Evaluador de Avería, Consultor y el Actuario

18.- En el artículo 3 “Conceptos", solamente se define al ajustador, al investigador de siniestro, y la evaluación de riesgos, pero no se define lo que debe entenderse como evaluador de avería, consultor y actuario.

19.- Los intermediarios y auxiliares de seguros están sujetos a la supervisión de la Superintendencia y sus actividades se sujetarán a las disposiciones de esta Ley y a las normas que con carácter general dicte el Consejo Directivo, correspondiéndole al Superintendente otorgar las autorizaciones para operar. El artículo 79 LGIS derogada, sujetaba a los corredores de seguros a la Ley y a las disposiciones del Código de Comercio en lo que les fuere aplicable.

20.- Tanto las personas naturales como las jurídicas que sea intermediarios, con excepción de los agentes de seguros o 
auxiliares de seguros, con excepción de los auxiliares internos, deben garantizar el cumplimiento de las responsabilidades en las que incurra frente al asegurado, beneficiario y de la sociedad de seguros, mediante una póliza de errores y omisiones, sin este requisito no pueden ejercer esta actividad. La aseguradora responde por las actuaciones de los agentes y los auxiliares internos. (art. 122).

21.- Toda aseguradora que quiera incluir un producto dentro de la categoría de seguros masivos debe pedir aprobación a la Superintendencia para hacerlo. Corresponde a ésta último calificarlo como seguro masivo.

La suscripción de este tipo de seguro por parte del representante de la aseguradora, podrá efectuarse mediante el uso de facsímil, previa resolución de su Junta Directiva aprobándola y estableciendo las regulaciones en cuanto a la seguridad y manejo de éste procedimiento. (art. 124). Las características que encontramos para que este seguro sea considerado masivo son: que sean pólizas sin mayor complejidad técnica y de fácil comprensión para el asegurado y que sea susceptible de estandarización.

22.- Las personas que deseen comercializar pólizas de seguros masivos, deberán contar con la aprobación del Superintendente e inscribirse en el registro de comercializadores de seguros masivos. (art. 125). No se señala la forma en que se van a distribuir estos seguros ya que estas empresas no pueden suscribir.

\section{En cuanto a las sanciones y multas administrativas:}

Las multas que más interesan son las señaladas por el incumplimiento a la Norma de Prevención del delito de Lavado de Dinero y las establecidas para los Intermediarios de Seguros.

23.- Sanciones para el incumplimiento de la Norma de Prevención del delito de Lavado de Dinero:

1.- Son las multas más altas del Título VII, oscilan de US $\$ 5,000.00$ a US\$ $60,000.00$ a excepción de las multas señaladas en la Norma por violación a los conflictos de interés (de US\$ 2,000.00 a US\$ 60,000.00, artículo 160), operaciones con partes relacionadas (de US\$ $5,000.00$ a US\$ 60,000.00, artículo 161) y sanciones por carecer de autorización (de US\$ 100.00 a US $\$ 100,000.00$ ).

2.- Cada unidad de multa equivale a un dólar de los Estados Unidos de Norteamérica y la Superintendencia no podrá aplicar sanciones distintas a las expresadas en la Ley 733. La Superintendencia graduará los montos de las multas según situación específica y su ponderación será de muy grave, grave y leve.

3.- Las multas están sujetas al criterio técnico de la Superintendencia. La imposición de multa nunca debe estar sujeta a criterios sino a hechos comprobados.

4.- Según la gravedad de la infracción las multas se impondrán de la siguiente forma:

4.1.- Persona sancionada: La sociedad aseguradora y/o la persona responsable, según cada caso.

Infracción:

a.- No desarrollar adecuadamente un Sistema Integral de Prevención del delito de Lavado de Dinero y del Financiamiento al Terrorismo (SIPAR/ LD/FT) o que dicho programa no se 
ajuste a las necesidades del giro de los riesgos del negocio o dicho programa sea deficiente en su contenido, especialmente en relación a su administración y ejecución.

b.- No cumplir con la obligación de reportar las operaciones inusuales o sospechosas. Y el hecho de no reportar una operación ostensiblemente sospechosa.

Sanción: Multa entre US\$ 5,000.00 y US\$ $60,000.00$

4.2.- Persona sancionada: El gerente, vicegerente, funcionario, administrador de prevención, empleados.

Infracción:

a.- Divulgar, alertar, informar al cliente o a otra persona, que su transacción o cualquier otra transacción, fue reportada mediante un Reporte de Operación Sospechosa a la UAF, o que está siendo analizada para este Reporte.

b.- No informar al Superintendente, o esconder información sobre hechos que impidan el adecuado desempeño de su labor, una vez que no haya sido resueltos por la Dirección de la Aseguradora pese a requerirse atención inmediata.

Sanción: Multa de 4 a 8 veces el salario respectivo, sin perjuicio de la remoción del cargo y las sanciones penales correspondientes.

\section{3.- Persona sancionada: Directivos.}

Infracción:

a.- Divulgar, alertar, informar al cliente o a otra persona, que su transacción o cualquier otra transacción, fue reportada como Reporte de Operación Sospechosa o que está siendo analizada para este reporte.

Sanción: Multa entre US\$ 5,000.00 y US\$ $50,000.00$

4.4.- Persona sancionada: Junta Directiva y Comité de Prevención.

Infracción: No de atención y respuesta a los requerimientos planteaos por el administrador de prevención, sobre hechos que impidan la adecuada implementación del Sistema Integral de Prevención.

Sanción: Multa entre US\% 5,000.00 y US\$ 50,000.00.

4.5.- Persona sancionada: Gerente, vicegerente.

Infracción: obstaculizar la labor y la capacitación del administrador de prevención o debilite el adecuado desarrollo de dicho programa.

Sanción: Multa entre US\$ 5,000.00 y US\$ $50,000.00$

\section{LEGISLACION COMPARADA:}

El Salvador: Sanciona con multa del 10\% del $2 \%$ del capital y reservas de capital de la aseguradora.

Honduras: Habla de multas de un monto máximo de 500,000.00 lempiras atendiendo la gravedad de la infracción.

Guatemala:Sanciona, la primera infracción, con multa de 500.00 a 40,000.00 Unidades de multa. La reincidencia con multa del doble de la primera y la tercera reincidencia con multa equivalente al doble de la última sanción. 
Costa Rica: sanciona con multa de hasta el $5 \%$ del patrimonio de la aseguradora al momento de la infracción concluyendo con la cancelación de la autorización para operar.

República Dominicana: sanciona con multas de 5 a 50 veces el salario mínimo privado de la persona que ha ocasionado la infracción.

Sanciones para los Intermediarios de Seguros:

Elartículo167señalaqueelSuperintendente conforme las causales que se establezcan en la norma correspondiente, podrá imponer a los Intermediarios de Seguros y Auxiliares de Seguros las siguientes sanciones: amonestación, multas de cien a cinco mil unidades de multa, suspensión de la autorización y revocación de la autorización, previa audiencia del Intermediario o el auxiliar de seguros, siguiendo el debido proceso.

\section{CONCLUSIONES}

1.- Muchos de los artículos de esta Ley, sobre todo los relativos a las autorizaciones de las aseguradoras y su administración y control, fueron copiados íntegros de la Ley General de Bancos. El resto fueron tomados de leyes extranjeras.

2.- A pesar de ser una Ley nueva $y$ moderna, contiene muchos vacíos y deficiencias, que deberán ser aclarados y resueltos por la Superintendencia de Bancos, lo que también considero contraproducente. En este sentido son más de 60 los Reglamentos que la Superintendencia va a dictar en ocasión de la entrada en vigencia de la Ley.
3.- Desparece en la nueva Ley la obligatoriedad de la intervención de un Intermediario de Seguro en la emisión de pólizas de incendio sobre bienes muebles y mercaderías. (art. 84 LGIS).

4.- Es Ley impone mayores obligaciones y cargas a los Intermediarios de Seguros que se manifiesta en la reducción de los plazos para entregar los documentos de los clientes y las primas (art. 119). Ahora es de tres días (sin especificar si son calendarios o hábiles), antes (art. 30 NRIS) era de cinco días hábiles; las contra garantías que el Intermediario debe entregar a la Aseguradora, para poder operar, es ahora una contra garantía real (art. 188), antes se permitían garantías personales o de otro tipo; las Agencias de Seguros, con la antigua LGSI, estaban autorizadas a intermediar seguros a nombre de una o varias aseguradoras (art. 80), ahora, con la nueva Ley, solamente pueden ofrecer los seguros de sola empresa aseguradora (art. 3) y con esta nueva Ley, los Intermediarios de Seguros están obligados al mantenimiento de la Superintendencia (art. 126), en el orden del $0.5 \%$ de sus ingresos totales anuales por comisiones, calculados al 31 de diciembre del año inmediato anterior.

\section{Referencias Bibliográficas}

1.- Ley 733, Ley General de Seguros, Reaseguros y Fianzas de Nicaragua.

2.- Ley Reguladora del Mercado de Seguros, de Costa Rica.

3.- $\quad$ Ley de la Actividad Aseguradora, de Guatemala. 
4.- $\quad$ Ley de Instituciones de Seguros y Reaseguros de Honduras.

5.- $\quad$ Ley de Sociedades de Seguro, del Salvador.

6.- Ley sobre Seguros y Fianzas, de República Dominicana.

7.- Norma Regulatoria para la Autorización de los Intermediarios de Seguros de Nicaragua. 